\title{
Promoter polymorphisms of DNA methyltransferase 3B and risk of hepatocellular carcinoma
}

\author{
YINGBIN LAO $^{1}$, HUAZHANG WU ${ }^{1}$, CHENGCHEGN ZHAO ${ }^{1}$, QUNYING WU ${ }^{2}$, \\ FENGCHANG QIAO ${ }^{1}$ and HONG FAN ${ }^{1}$
}

\author{
${ }^{1}$ Department of Medical Genetics and Developmental Biology, Medical School of Southeast University and \\ Key Laboratory of Developmental Genes and Human Diseases, Ministry of Education, Nanjing, Jiangsu 210009; \\ ${ }^{2}$ Institute of Biotechnology, Guilin Medical University, Guilin, Guangxi 541004, P.R. China
}

Received May 21, 2013; Accepted July 05, 2013

DOI: $10.3892 /$ br.2013.142

\begin{abstract}
Hepatocellular carcinoma (HCC) is one of the most common solid tumors worldwide. Epigenetic changes in gene expression, including DNA methylation and histone modifications, may contribute to the development of HCC. Polymorphisms of the DNA methyltransferase $3 B$ (DNMT3B) gene may affect the activity of this enzyme and increase the susceptibility to several types of cancer, including HCC. To confirm this hypothesis, we investigated the association between single-nucleotide polymorphisms-149C $>\mathrm{T}$ ( $\mathrm{rs} 2424913)$ and $-579 \mathrm{G}>\mathrm{T}$ (rs1569686) in the promoter region of DNMT3B and the risk of HCC. DNMT single-nucleotide polymorphisms (SNPs) were genotyped by polymerase chain reaction-restriction fragment length polymorphism in $108 \mathrm{HCC}$ patients and 240 healthy controls matched for age, gender and ethnicity. The DNMT3B-149 TT genotype was not significantly associated with an increased risk of HCC. The frequency of DNMT3B-149C was $0.46 \%$ in HCC patients and $1.39 \%$ in healthy individuals, whereas the frequency of DNMT3B-579G was $8.33 \%$ in $\mathrm{HCC}$ patients and $10.42 \%$ in healthy individuals. No significant differences were observed in the genotype or allelic distribution between HCC patients and controls. In conclusion, DNMT3B-149C $>$ T and $-579 \mathrm{G}>\mathrm{T}$ polymorphisms are not significantly associated with an increased risk of HCC. These results demonstrated that these particular SNPs may not be used as biomarkers to predict susceptibility to HCC.
\end{abstract}

Correspondence to: Professor Hong Fan, Department of Medical Genetics and Developmental Biology, Medical School of Southeast University and Key Laboratory of Developmental Genes and Human Diseases, Ministry of Education, 87 Dingjiaqiao, Gulou, Nanjing, Jiangsu 210009, P.R. China

E-mail: fanh@seu.edu.cn

Abbreviations: PCR, polymerase chain reaction; RFLP, restriction fragment length polymorphism; OR, odds ratio; CI, confidence interval; HCC, hepatocellular carcinoma; SNP, single-nucleotide polymorphism

Key words: hepatocellular carcinoma, DNA methyltransferase 3B, single-nucleotide polymorphism, susceptibility

\section{Introduction}

Hepatocellularcarcinoma (HCC) is the sixth most common type of cancer, the third leading cause of cancer-related mortality worldwide and the second leading cause of cancer-related mortality in China $(1,2)$. The cause of HCC is a complex interplay between numerous factors (3). Accumulating evidence in molecular genetics indicate that single-nucleotide polymorphisms (SNPs) in immune response-, angiogenesis- and tumorigenesis-related genes are associated with susceptibility to HCC (4-7). Recent advances in genome-wide association studies also identified new susceptibility loci for $\operatorname{HCC}(8,9)$, which may help elucidate the underlying mechanism of genetic variations in the development of HCC.

Recent investigations on gene methylation utilizing genome- wide techniques revealed that a large number of genes exhibit aberrant DNA methylation profiles in cancer (10). These changes may be used to stratify cancer subtypes and predict cancer outcomes $(11,12)$. DNA methyltransferase 3B (DNMT3B) plays a crucial role in embryonic development and aberrant DNA methylation in carcinogenesis. Polymorphisms of the DNMT3B gene may regulate gene expression, affect enzymatic activity and contribute to the susceptibility to cancer. It was previously demonstrated that certain SNPs in the DNMT3B gene may affect DNMT3B activity on DNA methylation, thereby modulating the susceptibility to cancer (13). The DNMT3B-149C $>$ T polymorphism confers a $30 \%$ increase in promoter activity in vitro $(14,15)$. DNMT3B promoter polymorphisms were previously reported to be associated with the risk of lung, colorectal and head and neck cancer $(14,16)$. Based on the evidence mentioned above, we used a candidate gene strategy and screened variations in the DNMT3B gene to investigate the association between these variations and $\mathrm{HCC}$ susceptibility in a Chinese population.

\section{Materials and methods}

Subjects. The patients and control subjects in this study were recruited between September, 2006 and June, 2008 from the Jiangsu Tumor Hospital in the Jiangsu province. Cases and controls were matched by age and gender. The characteristics of the cases and controls are presented in detail in 
Table I. Characteristics of the study population.

A, DNMT3B-149C $>$ T

\begin{tabular}{lcc}
\hline Variables & HCC cases $(\%)(\mathrm{n}=108)$ & Controls $(\%)(\mathrm{n}=216)$ \\
\hline Age (years) & & $56(25.93)$ \\
$<50$ & $35(32.41)$ & $160(74.07)$ \\
$\geq 50$ & $73(67.59)$ & \\
Gender & & $152(70.37)$ \\
Male & $85(78.70)$ & $64(29.63)$ \\
Female & $23(21.3)$ & 0.111 \\
\hline
\end{tabular}

\section{B, DNMT3B-579G $>$ T}

\begin{tabular}{lcc}
\hline Variables & HCC cases $(\%)(\mathrm{n}=114)$ & Controls $(\%)(\mathrm{n}=240)$ \\
\hline Age (years) & & \\
$<60$ & $62(54.39)$ & $122(50.83)$ \\
$\geq 60$ & $52(45.61)$ & $118(49.17)$ \\
Gender & & \\
Male & $90(78.95)$ & $70(70.83)$ \\
Female & $24(21.05)$ & $70(29.17)$ \\
\hline
\end{tabular}

DNMT3B, DNA methyltransferase 3B; HCC, hepatocellular carcinoma.

Table I A and B. Samples were obtained following written consent and analyzed anonymously. This study was performed with the approval of the Medical Ethics Committee of the Medical School of Southeast University.

DNA extraction. Venous blood samples $(5 \mathrm{ml})$ were collected from HCC patients and healthy control subjects in EDTA vacuum tubes. Genomic DNA was extracted from white blood cells within 1 week after sample collection by proteinase $\mathrm{K}$ digestion, as previously described (17).

DNMT3B SNP genotyping. The DNMT3B-149C $>\mathrm{T}$ and $-579 \mathrm{G}>\mathrm{T}$ SNPs were analyzed by polymerase chain reaction-restriction fragment length polymorphisms (PCR-RFLPs). The PCR was performed in a $25-\mu \mathrm{l}$ volume containing $100 \mathrm{ng}$ genomic DNA, $2.5 \mu 1$ 10X PCR buffer, $2.0 \mathrm{mM} \mathrm{MgCl}_{2}$, $0.1 \mathrm{mM}$ dNTPs (mixture of dATP, dTTP, dCTP and dGTP), 10 pmol of each primer (DNMT3B-149C $>$ T primer: forward 5'-TGCTGTGACAGGCAGAGCAG-3' and reverse 5'-GGT AGCCGGGAACTCCACGG-3'; DNMT3B-579G>T primer: forward 5'-GAGGTCTCATTATGCCTAGG-3' and reverse 5'-GGGAGCTCACCTTCTAGAAA-3'), 1 unit of Taq DNA polymerase (Biocolor BioScience and Technology Co., Shanghai, China). The PCR cycle conditions consisted of an initial denaturation step at $95^{\circ} \mathrm{C}$ for $5 \mathrm{~min}$, followed by 30 cycles at $95^{\circ} \mathrm{C}$ for $30 \mathrm{sec}$, at $62^{\circ} \mathrm{C}$ for $30 \mathrm{sec}(-149 \mathrm{C}>\mathrm{T})$ or at $57^{\circ} \mathrm{C}$ for $30 \mathrm{sec}$ $(-579 \mathrm{G}>\mathrm{T})$ and at $72^{\circ} \mathrm{C}$ for $30 \mathrm{sec}$, with a final elongation step at $72^{\circ} \mathrm{C}$ for $5 \mathrm{~min}$. The 380-bp (DNMT3B-149C $>\mathrm{T}$ ) fragment was digested with $B \ln \mathrm{I}$ for $5 \mathrm{~min}$ at $37^{\circ} \mathrm{C}$, the digested products were separated on $2.0 \%$ agarose gel and the PCR-RFLP bands were visualized under UV light with ethidium bromide staining. The
T allele has a $B \ln I$ restriction site that resulted in two bands (207and 173-bp) in the homozygous genotype, the heterozygote exhibited three bands (380-, 207- and 173-bp), whereas the variant $\mathrm{C}$ allele produced only one band representing the entire 380-bp fragment. The $-579 \mathrm{G}>\mathrm{T}$ polymorphism was determined by PCR-RFLPs. PvuII was used to detect the G-T transition. The DNMT3B T/T genotype was expected to exhibit two DNA bands at the positions of 132 and $93 \mathrm{bp}$, whereas the G/G genotype was expected to exhibit a single band (at $225 \mathrm{bp}$ ) and the heterozygote was expected to exhibit 3 bands (at 225, 132 and $93 \mathrm{bp}$ ). PCR was conducted and the results were evaluated without knowledge of the case-control status. The samples were successfully genotyped. For genotyping quality control, $5 \%$ of the samples were randomly selected and directly sequenced to obtain $100 \%$ identical results.

Statistical analysis. Data were analyzed with SPSS software, version 13.0 (SPSS Inc., Chicago, IL, USA). Patients and controls were compared using the Student's t-test for continuous variables and the Chi-square $\left(\chi^{2}\right)$ test for categorical variables. Allele and genotype frequencies between control subjects and HCC patients were obtained using the Chi-square test and the standard goodness-of-fit test was used to assess the Hardy-Weinberg equilibrium. $\mathrm{P}<0.05$ was considered to indicate a statistically significant difference.

\section{Results}

The demographics of the cases and controls enrolled in this study are provided in Tables I A and B. No significant differences were observed in age and gender distribution between 
Table II. DNMT3B-149C>T genotype and allele frequency and distribution.

A, DNMT3B-149C>T genotype and allele frequency among cases and controls

\begin{tabular}{|c|c|c|c|c|c|c|}
\hline \multirow[b]{2}{*}{ Genotype/allele } & \multicolumn{2}{|c|}{$\mathrm{HCC}(\mathrm{n}=108)$} & \multicolumn{2}{|c|}{ Control subjects $(n=216)$} & \multirow[b]{2}{*}{ Crude OR (95\% CI) } & \multirow[b]{2}{*}{ P-value ${ }^{a}$} \\
\hline & No. & $(\%)$ & No. & $(\%)$ & & \\
\hline \multicolumn{7}{|l|}{ Genotype } \\
\hline TT & 107 & 99.07 & 210 & 97.22 & 1 & \\
\hline $\mathrm{CT}$ & 1 & 0.93 & 6 & 2.78 & $0.327(0.039-2.752)$ & $0.499^{\mathrm{b}}$ \\
\hline $\mathrm{CC}$ & $0^{c}$ & 0.00 & 0 & 0.00 & - & \\
\hline \multicolumn{7}{|l|}{ Allele } \\
\hline $\mathrm{C}$ & 1 & 0.46 & 6 & 1.39 & 1 & \\
\hline $\mathrm{T}$ & 215 & 99.54 & 426 & 98.61 & $3.028(0.362-25.313)$ & $0.502^{\mathrm{d}}$ \\
\hline
\end{tabular}

B, Distribution of-149C $>$ T DNMT3B genotypes and association with age and gender in HCC cases

\begin{tabular}{|c|c|c|c|c|c|}
\hline \multirow[b]{2}{*}{ Groups } & \multicolumn{3}{|c|}{ Genotype } & \multirow{2}{*}{$\frac{\text { Allele }}{\mathrm{T}(\%)}$} & \multirow[b]{2}{*}{ P-value } \\
\hline & $\mathrm{CC}(\%)$ & CT (\%) & TT (\%) & & \\
\hline Age (years) & $0(0.00)$ & $1(0.93)$ & 107 (99.07) & 99.07 & \\
\hline$<50$ & $0(0.00)$ & $0(0.00)$ & $35(32.40)$ & 100.00 & $1.000^{f}$ \\
\hline$\geq 50$ & $0(0.00)$ & $1(10.93)$ & $72(66.67)$ & 98.63 & \\
\hline \multicolumn{6}{|l|}{ Gender } \\
\hline Male & $0(0.00)$ & $0(0.00)$ & 85 (78.70) & 100.00 & $0.213^{\mathrm{g}}$ \\
\hline Female & $0(0.00)$ & $1(0.93)$ & $22(20.37)$ & 95.65 & \\
\hline
\end{tabular}

${ }^{\mathrm{a} C h i}$-square $\left(\chi^{2}\right)$ test; ${ }^{\mathrm{b}} \mathrm{HCC}$ cases vs. controls; ${ }^{\mathrm{c}} \mathrm{CC}$ genotype not detected in HCC patients and control subjects; ${ }^{\mathrm{d}} \mathrm{T}$ allele vs. C allele; ${ }^{\text {e }}$ Chi-square $\left(\chi^{2}\right)$ test; ffrequency of the T allele in individuals aged $<50$ vs. $\geq 50$ years; sfrequency of the T allele in male vs. female individuals. DNMT3B, DNA methyltransferase 3B; HCC, hepatocellular carcinoma; OR, odds ratio; CI, confidence interval.

cases and controls, suggesting that the matching based on these two variables was adequate. There was no evidence of deviation from the Hardy-Weinberg equilibrium among the cases or controls. The genotypic and allelic frequencies of DNMT3B-149C $>$ T are provided in Table II A. No significant differences were found in the genotypic and allelic frequencies between the two groups. Subsequently, we stratified the HCC cases by age and gender and no significantly different frequencies of $-149 \mathrm{C}>\mathrm{T}$ were observed (Table II B).

As regards DNMT3B-579G $>$ T, the distributions of the polymorphism genotypes among the HCC cases (TT, 83.33\%; GT, 16.67\%; and GG, $0 \%$ ) exhibited no significant differences from those among the controls (TT, 80.83\%; GT, 17.50\%; and GG, $1.67 \%$; $\mathrm{P}>0.05$ ). No significant differences in allelic frequencies were observed between the two groups (Table III A). The stratified analysis revealed no significant difference in the distribution of the $-579 \mathrm{G}>\mathrm{T}$ genotype according to age or gender in the HCC patients (Table III B).

\section{Discussion}

HCC is one of the most common malignant tumors, has a poor survival rate and is particularly prevalent in China, as well as in the rest of Asia. The identification of biomarkers for the early diagnosis and accurate prognosis of HCC is crucial for improving patient survival. Numerous tissue and serum markers associated with invasiveness, metastasis, recurrence and potential prognostic significance have been identified in HCC thus far $(18,19)$.

In mammals, DNMT3B plays an important role in carcinogenesis and DNMT SNPs are important indicators of the genetic susceptibility to cancer development. Therefore, genetic polymorphism assays have been used to investigate the aetiology of malignant diseases (20). The significance of DNMT3B promoter genetic polymorphisms for tumorigenesis has been extensively investigated, although no consensus was reached due to the differences in tumors, ethnic groups, geographical areas or sample size between individual studies. A meta-analysis demonstrated that the $-149 \mathrm{C}>\mathrm{T}$ polymorphism of DNMT3B was not associated with colorectal cancer risk (21). It has also been demonstrated that the $-579 \mathrm{G}>\mathrm{T}$ SNP of the DNMT3B promoter decreased the susceptibility to lung and colon cancer $(22,23)$, suggesting that the DNMT3B promoter $-579 \mathrm{G}>\mathrm{T}$ polymorphism may be used as a genetic risk factor to evaluate the population susceptible to tumor development. Khorshied and El-Ghamrawy (24) and Zhao et al (25) demonstrated that the DNMT3B $-579 \mathrm{G}>\mathrm{T}$ polymorphism represents a novel genetic risk factor for idiopathic thrombocytopenic 
Table III. DNMT3B-579G>T genotype and allele frequency and distribution.

A, DNMT3B-579G>T genotype and allele frequency among cases and controls

\begin{tabular}{|c|c|c|c|c|c|c|}
\hline \multirow[b]{2}{*}{ Genotype/allele } & \multicolumn{2}{|c|}{$\mathrm{HCC}(\mathrm{n}=114)$} & \multicolumn{2}{|c|}{ Control subjects $(n=240)$} & \multirow[b]{2}{*}{ Crude OR (95\% CI) } & \multirow[b]{2}{*}{ P-value ${ }^{a}$} \\
\hline & No. & $(\%)$ & No. & $(\%)$ & & \\
\hline \multicolumn{7}{|l|}{ Genotype } \\
\hline GT (ref.) & 19 & 16.67 & 42 & 17.50 & 1 & \\
\hline TT & 95 & 83.33 & 194 & 80.83 & $1.082(0.597-1.962)$ & $0.794^{\mathrm{b}}$ \\
\hline GG & $0^{c}$ & - & 4 & 1.67 & $1.452(1.227-1.719)$ & 0.448 \\
\hline \multicolumn{7}{|l|}{ Allele } \\
\hline G & 19 & 8.33 & 50 & 10.42 & 1.000 & \\
\hline $\mathrm{T}$ & 209 & 91.67 & 430 & 89.58 & $1.279(0.735-2.225)$ & $0.382^{\mathrm{d}}$ \\
\hline
\end{tabular}

B, Distribution of DNMT3B-579G > T genotypes and allele frequencies among HCC cases and association with age and gender

\begin{tabular}{|c|c|c|c|c|c|}
\hline \multirow[b]{2}{*}{ Groups } & \multicolumn{3}{|c|}{ Genotype } & \multirow{2}{*}{$\frac{\text { Allele }}{\mathrm{T}(\%)}$} & \multirow[b]{2}{*}{$\mathrm{P}$-value } \\
\hline & GG $(\%)$ & GT (\%) & $\mathrm{TT}(\%)$ & & \\
\hline Total & $0(0.00)$ & $19(16.67)$ & $95(83.33)$ & 91.67 & \\
\hline \multicolumn{6}{|c|}{ Age(years) } \\
\hline$<50$ & $0(0.00)$ & $12(10.53)$ & $50(43.86)$ & 90.32 & $0.423^{\mathrm{f}}$ \\
\hline$\geq 50$ & $0(0.00)$ & $7(6.14)$ & 45 (39.47) & 93.27 & \\
\hline \multicolumn{6}{|l|}{ Gender } \\
\hline Male & $0(0.00)$ & $14(12.28)$ & 76 (66.67) & 92.22 & $0.919^{g}$ \\
\hline Female & $0(0.00)$ & $5(4.39)$ & 19 (16.67) & 89.58 & \\
\hline
\end{tabular}

${ }^{\mathrm{a} C h i}$-square $\left(\chi^{2}\right)$ test; ${ }^{\mathrm{b}} \mathrm{HCC}$ cases vs. controls; ${ }^{\mathrm{c}} \mathrm{GG}$ genotype not detected in HCC patients; ${ }^{\mathrm{d}} \mathrm{G}$ allele vs. T allele; ${ }^{\mathrm{e}} \mathrm{Chi}-\mathrm{square}\left(\chi^{2}\right)$ test;

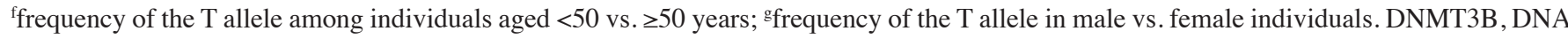
methyltransferase 3B; HCC, hepatocellular carcinoma; OR, odds ratio; CI, confidence interval.

purpura. However, it was also reported that there is no association between the $-579 \mathrm{G}>\mathrm{T}$ polymorphism and head and neck squamous cell carcinoma or esophageal carcinoma (26,27). A meta-analysis for $-149 \mathrm{C}>\mathrm{T}$ and $-579 \mathrm{G}>\mathrm{T}$ suggested that there was no evidence that individuals carrying the variant genotypes $(\mathrm{CC}+\mathrm{CT})$ have an increased risk of cancer compared to those carrying the wild homozygote TT genotype, although $-579 \mathrm{G}>\mathrm{T}$ was associated with a significantly decreased risk of cancer (28).

However, little is known about the association between the polymorphisms of the DNMT3B promoter and HCC. Therefore, we conducted a case-control study to investigate the association of the DNMT3B promoter $-149 \mathrm{C}>\mathrm{T}$ and $-579 \mathrm{G}>\mathrm{T}$ polymorphisms with genetic susceptibility to $\mathrm{HCC}$ and evaluate whether these SNPs may act as biomarkers to predict the susceptibility to $\mathrm{HCC}$ in a Chinese population. $\mathrm{Wu}$ and Lin (29) reported that DNMT3B-149C $>$ T polymorphism was not associated with an increased risk of HCC in a Chinese population and Ezzikouri et al (30) demonstrated that the DNMT3B-149C >T genotype was not significantly associated with an increased risk of HCC in a Moroccan population. Our results are consistent with those of Wu and Lin (29) and Ezzikouri et al (30), with insignificant differences in genotype and allele frequency distribution between HCC patients and control subjects suggesting that these two particular SNPs are not associated with the risk of HCC in the study population.

To the best of our knowledge, this is the first study to investigate the association of DNMT3B-149C $>$ T and $-579 \mathrm{G}>\mathrm{T}$ polymorphisms with genetic susceptibility to HCC. Our results suggest that the $-149 \mathrm{C}>\mathrm{T}$ and $-579 \mathrm{G}>\mathrm{T}$ polymorphisms do not affect the risk for HCC, at least in the Chinese population. This finding may provide valuable insight into hepatocellular carcinogenesis. However, a larger population has to be investigated and evaluated to elucidate the contribution of DNMT3B SNPs to the susceptibility to HCC in Chinese individuals. Furthermore, to elucidate the true effects of DNMT3B polymorphisms on determining the pathogenesis of HCC, investigations of other variants of DNMT3B (including promoter and coding regions) and their effects on the biological functions of DNMTs are also required.

\section{Acknowledgements}

This study was supported by the National Natural Science Foundation of China (grant no. 81171915) and the QingLan Project of Jiangsu Province. 


\section{References}

1. Wang Z, Cao Y, Jiang C, et al: Lack of association of two common polymorphisms rs2910164 and rs11614913 with susceptibility to hepatocellular carcinoma: a meta-analysis. PLoS One 7: e40039, 2012.

2. Thomas MB, Jaffe D, Choti MM, et al: Hepatocellular carcinoma: consensus recommendations of the National Cancer Institute Clinical Trials Planning Meeting. J Clin Oncol 28: 3994-4005, 2010.

3. Chen CJ and Chen DS: Interaction of hepatitis B virus, chemical carcinogen, and genetic susceptibility: multistage hepatocarcinogenesis with multifactorial etiology. Hepatology 36: 1046-1049, 2002.

4. Kong SY, Park JW, Lee JA, et al: Association between vascular endothelial growth factor gene polymorphisms and survival in hepatocellular carcinoma patients. Hepatology 46: 446-455, 2007.

5. Deng G, Zhou G, Zhang R, et al: Regulatory polymorphisms in the promoter of CXCL10 gene and disease progression in male hepatitis B virus carriers. Gastroenterology 134: 716-726, 2008.

6. Clifford RJ, Zhang J, Meerzaman DM, et al: Genetic variations at loci involved in the immune response are risk factors for hepatocellular carcinoma. Hepatology 52: 2034-2043, 2010.

7. Long XD, Ma Y, Zhou YF, et al: Polymorphism in xeroderma pigmentosum complementation group $\mathrm{C}$ codon 939 and aflatoxin B1-related hepatocellular carcinoma in the Guangxi population. Hepatology 52: 1301-1309, 2010.

8. Kumar V, Kato N, Urabe Y, et al: Genome-wide association study identifies a susceptibility locus for $\mathrm{HCV}$-induced hepatocellular carcinoma. Nat Genet 43: 455-458, 2011.

9. Zhang H, Zhai Y, Hu Z, et al: Genome-wide association study identifies 1 p36.22 as a new susceptibility locus for hepatocellular carcinoma in chronic hepatitis B virus carriers. Nat Genet 42 : $755-758,2010$.

10. Figueroa ME, Lugthart S, Li Y, et al: DNA methylation signatures identify biologically distinct subtypes in acute myeloid leukemia. Cancer Cell 17: 13-27, 2010.

11. Noushmehr H, Weisenberger DJ, Diefes K, et al: Identification of a $\mathrm{CpG}$ island methylator phenotype that defines a distinct subgroup of glioma. Cancer Cell 17: 510-522, 2010.

12. Portela A and Esteller M: Epigenetic modifications and human disease. Nat Biotechnol 28: 1057-1068, 2010.

13. Esteller M: Epigenetics in cancer. N Engl J Med 358: 1148-1159, 2008.

14. Shen H, Wang L, Spitz MR, et al: A novel polymorphism in human cytosine DNA-methyltransferase-3B promoter is associated with an increased risk of lung cancer. Cancer Res 62: 4992-4995, 2002.
15. Wang L, Rodriguez M, Kim ES, et al: A novel C/T polymorphism in the core promoter of human de novo cytosine DNA methyltransferase 3B6 is associated with prognosis in head and neck cancer. Int J Oncol 25: 993-999, 2004

16. Taberlay PC and Jones PA: DNA methylation and cancer. Prog Drug Res 67: 1-23, 2011

17. Miller SA, Dykes DD and Polesky HF: A simple salting out procedure for extracting DNA from human nucleated cells. Nucleic Acids Res 16: 1215, 1988.

18. Paz MF, Fraga MF, Avila S, et al: A systematic profile of DNA methylation in human cancer cell lines. Cancer Res 63: 1114-1121, 2003.

19. Egger G, Liang G, Aparicio A, et al: Epigenetics in human disease and prospects for epigenetic therapy. Nature 429: 457-463, 2004.

20. Wjst M: Target SNP selection in complex disease association studies. BMC Bioinformatics 5: 92, 2004

21. Fang C, Sun W, Han H, et al: The $-149 \mathrm{C}>\mathrm{T}$ polymorphism of DNMT3B is not associated with colorectal cancer risk: Evidence from a meta-analysis based on case-control studies. Exp Ther Med 4: 728-732, 2012

22. Lee SJ, Jeon HS, Jang JS, et al: DNMT3B polymorphisms and risk of primary lung cancer. Carcinogenesis 26: 403-409, 2005.

23. Hong YS, Lee HJ, You CH, et al: DNMT3b 39179GT polymorphism and the risk of adenocarcinoma of the colon in Koreans. Biochem Genet 45: 155-163, 2007.

24. Khorshied MM and El-Ghamrawy MK: DNA methyltransferase 3B (DNMT3B -579G $>$ T) promotor polymorphism and the susceptibility to pediatric immune thrombocytopenic purpura in Egypt. Gene 511: 34-37, 2012.

25. Zhao H, Du W, Gu D, et al: DNMT3B 579G $>$ T promoter polymorphism and the risk for idiopathic thrombocytopenic purpura in a Chinese population. Acta Haematol 122: 31-35, 2009.

26. Chang KP, Hao SP, Liu CT, et al: Promoter polymorphisms of DNMT3B and the risk of head and neck squamous cell carcinoma in Taiwan: a case-control study. Oral Oncol 43: 345-351, 2007.

27. Fan H, Liu DS, Zhang SH, et al: DNMT3B $579 \mathrm{G}>\mathrm{T}$ promoter polymorphism and risk of esophagus carcinoma in Chinese. World J Gastroenterol 14: 2230-2234, 2008.

28. Zhu S, Zhang H, Tang Y, et al: DNMT3B polymorphisms and cancer risk: a meta analysis of 24 case-control studies. Mol Biol Rep 39: 4429-4437, 2012.

29. Wu Y and Lin JS: DNA methyltransferase 3B promoter polymorphism and its susceptibility to primary hepatocellular carcinoma in the Chinese Han nationality population: a case-control study. World J Gastroenterol 13: 6082-6086, 2007.

30. Ezzikouri S, El Feydi AE, Benazzouz M, et al: Single nucleotide polymorphism in DNMT3B promoter and its association with hepatocellular carcinoma in a Moroccan population. Infect Genet Evol 9: 877-881, 2009. 